\title{
La política frentista \\ del peronismo renovador durante los años ochenta. Las coaliciones con la centroizquierda
}

\author{
The political alliances of the Peronism during the eighties. \\ Its coalitions with the center left
}

\section{Marcela Patricia Ferrari*}

\footnotetext{
* Doctora en Historia (École des Hautes Études en Sciences Sociales, París), y magíster en Historia (Universidad Nacional de Mar del Plata [UNMdP], Argentina). Investigadora independiente del CONICET. Profesora titular en el Departamento de Historia y directora del Centro de Estudios Históricos (CEHis) de la Facultad de Humanidades, en la UNMdP.

$\triangle \cdot$ marcelapatriciaferrari@gmail.com
}

RECIBIDO: [28.12.2016]

ACEPTADO: [14.4.2017]

\section{Resumen}

Las coaliciones electorales de Argentina fueron un tema que las ciencias sociales abordaron preferentemente para los últimos años noventa. Este artículo las analiza una década antes, colocando la lente en los frentes integrados por la Renovación Peronista y dos partidos o fracciones de centroizquierda: el Partido Demócrata Cristiano y el Partido Intransigente. La aproximación se realiza en clave histórica y en un juego de escalas que repara en dimensiones nacionales y de la provincia de Buenos Aires. A la luz de fuentes periodísticas y partidarias, dialoga con la hipótesis que sugiere que la gravitación del polo peronista impidió la consolidación de fuerzas de centro capaces de constituirse en alternativas electorales a partir de la recuperación democrática. Indaga en los motivos que llevaron a estos partidos a organizar coaliciones y se pregunta si eran meras alianzas destinadas a obtener mejores resultados electorales o si perseguían fines políticos más amplios, sostenidos en ideas, creencias o experiencias afines. Analiza los beneficios y los costos que los partidos debieron afrontar, 
los desafíos de los líderes que propiciaron esas coaliciones y las consecuencias que acarrearon esas alianzas para la dinámica interpartidaria.

Palabras clave: historia política, partido político, Argentina.

\begin{abstract}
The political alliances of the Peronism during the eighties. Its coalitions with the center left. The electoral coalitions of Argentina were a topic that the social sciences approached preferably for the last nineties. This article analyzes them a decade before, focusing the lens in the fronts integrated by the Renovation Peronist and two parties or fractions of center left: the Christian Democratic Party and the Intransigent Party. The approximation is realized in historical key and in a game of national and provincial scales. In the light of journalistic and partial sources, it talk with the hypothesis suggesting that the gravitation of the pole Peronist prevented the consolidation of forces of center capable of being constituted in electoral alternatives from the democratic recovery. It investigates in the motives that led to these parties to organizing coalitions and wonders if they were mere alliances destined to obtain better electoral results or if they were chasing more wide political aims supported in ideas, beliefs or related experiences. It analyze the benefits and the costs that the parties should have confronted, the challenges of the leaders who propitiated these coalitions and the consequences of these alliances for the political dynamics.
\end{abstract}

Keywords: political history, political parties, Argentine

\title{
Introducción
}

Después de las elecciones de la reapertura democrática de 1983, en las que el Partido Justicialista (PJ) se presentó individualmente a los comicios y perdió la presidencia de la Nación y la gobernación de su principal bastión, la provincia de Buenos Aires, por primera vez en elecciones libres de toda proscripción, el peronismo quedó sumido en una profunda crisis de la que comenzó a recuperarse desde 1985, de la mano de la denominada corriente renovadora. Ese proceso se tornó claro en 1987, a raíz de los amplios triunfos en las elecciones de gobernadores y legislativas, y mostró su eficacia cuando en 1989 consagró un presidente peronista. Pero esa recuperación no fue transitada en solitario. Tanto las disputas internas como la recuperación electoral fueron resueltas en buena medida gracias a la confluencia de un conjunto de partidos menores en los frentes electorales encabezados por el peronismo o alguna de sus fracciones. 
Poco se ha indagado acerca de esas particulares alianzas de los años ochenta. En efecto, tal como se ha señalado (Tcach, 2011), la literatura sobre coaliciones en Argentina anterior a 2001 se aboca, salvo excepciones (Clerici, 2013), a la década de 1990 (Abal Medina, 2007; Jozami, 2004; Novaro, 2002; Novaro y Palermo, 1998; Ollier, 2001), cuando esas prácticas reconocen una larga trayectoria en la historia política del país. ${ }^{1}$ Lo que nos interesa recuperar en este texto es cómo se construyeron coaliciones en la temprana recuperación democrática en perspectiva histórica y a la luz de algunos supuestos que aproximaron aquellos análisis. Uno de ellos es que el peronismo fue capaz de absorber sucesivamente en beneficio propio a los votantes de partidos de centro-izquierda, como el PI, de centro-derecha, como la Unión de Centro Democrático (UCEDÉ) y de un partido antisistema de derecha con arraigo en los sectores bajos del conurbano bonaerense, como el Movimiento por la Dignidad y la Independencia (ModiN) (Malamud, 2004, pp. 24 y 26). ${ }^{2}$ Otro podría atribuirse a que incorporaciones tan diferentes habrían sido posibles en virtud de la flexibilidad (Mustapic, 2002; Levitsky, 2005) y la vocación de poder que combinaba el peronismo (Malamud, 2004). Esto se acoplaría con las limitaciones de las fuerzas partidarias no peronistas a la hora de canalizar el voto de centro-izquierda y centro-derecha para constituirse en organizaciones estables, duraderas y, luego, en alternativas de gobierno, ante lo cual el peronista se constituye en un polo de gravitación y permanencia bastante más estable que el no peronista (Torre, 2002). Así, es posible suponer que el peronismo, en cuanto movimiento abarcador de un amplio abanico extendido de la izquierda a la derecha del espectro político y de arriba abajo de la escala social (Ostiguy, 1997), habría sido capaz de aglutinar $y$ absorber a partidos minoritarios al liderar coaliciones político-electorales que, es posible sostener, lo habrían llevado a posicionarse como una especie particular de partido toma todo, entre predominante y hegemónico — siguiendo respectivamente las tipologías de Kirchheimer (1990) y Sartori (1987)-.

Pero no mucho más que eso. Otros aspectos referidos a las coaliciones articuladas por el peronismo permanecen prácticamente desconocidos y suscitan una serie de preguntas: ¿Cuáles eran los motivos concretos que llevaron a un partido mayoritario como el PJ a organizar coaliciones y cuáles los que impulsaron a los partidos minoritarios a formar parte de ellas? ¿Eran meras alianzas destinadas a obtener un mejor resultado electoral a cambio de lo cual el partido predominante distribuía algunos

1 Por solo citar algunos ejemplos, para la Argentina del régimen oligárquico de fines de siglo XIX, cf. Alonso, 2010. Sobre la Concordancia de la década de 1930, cf. Macor, 2001. Los principales partidos de matriz movimientista (radicalismo y peronismo) evolucionaron de experiencias coalicionales multinivel exitosas; cf. Persello, 2004; Macor y Tcach, 2003 y 2013; Aelo, 2012.

2 Existe una presunción generalizada en cuanto a la existencia de una coalición institucional, no electoral, entre el PJ y la UCEDÉ. En la provincia de Buenos Aires durante el período analizado esto no resulta evidente. En 1987 la Alianza de Centro obtuvo 291.589 sufragios; en las elecciones de 1989, 240.870. 
cargos a sus socios menores, o también perseguían fines políticos más amplios sostenidos en ideas, creencias o experiencias afines? ¿Qué beneficios obtuvieron los partidos incorporados a esos frentes y qué costos debieron afrontar? ¿Qué desafíos asumieron los líderes que propiciaron esas coaliciones? ¿Qué consecuencias acarrearon esas alianzas para la dinámica interpartidaria?

La respuesta a estos interrogantes excede este trabajo. De ahí que se haya restringido el análisis a las alianzas electorales integradas por la llamada renovación peronista y dos partidos de centroizquierda o algunas de sus fracciones: el Partido Demócrata Cristiano (DC) y el Partido Intransigente (PI) en clave histórica y en un juego de escalas que repara en dimensiones nacionales y de la provincia de Buenos Aires. A la luz de fuentes periodísticas y partidarias, se pretende dialogar con la hipótesis de Juan Carlos Torre (2002) que sugiere que la gravitación del polo peronista impidió la consolidación de fuerzas de centro capaces de constituirse en alternativas electorales a partir de la recuperación democrática.

\section{Los frentes peronistas de los años ochenta}

La noción de frente es una categoría utilizada por el PJ para referir a una práctica de larga data en sus filas, las alianzas político-electorales, que esta organización nunca definió con claridad. A la salida de la dictadura esas alianzas eran reguladas por la ley de partidos políticos (n. ${ }^{\circ}$ 9889/82). Para ser reconocidas, las autoridades de los partidos que pretendían integrarlas debían manifestarse ante el órgano de aplicación competente dos meses antes de la elección y presentar la constancia de que la alianza había sido resuelta por los organismos directivos de las entidades, establecer el nombre adoptado, elevar la plataforma electoral, los mecanismos de selección de las candidaturas, los nombres de los apoderados, las listas de candidatos y declarar un número mínimo de afiliados. ${ }^{3}$

En esa coyuntura el PJ se encontraba sumido en fuertes conflictos derivados principalmente de la muerte de su líder y de las dificultades de procesar los enfrentamientos internos que se arrastraban, al menos, desde los años setenta. En la provincia de Buenos Aires, la rama sindical ubicada más a la derecha del espectro partidario logró controlar la organización, con fuertes resistencias de un sector de la rama política favorable a la democratización del justicialismo. Esa lucha ralentizó la elección de candidaturas provinciales y de congresales nacionales hasta fines de agosto; derivado

3 «Decreto-ley n. 9889/82 Orgánica de los partidos políticos y agrupaciones municipales». Boletín Oficial, 10.12.1982. Partidos políticos. Ordenado posteriormente por decreto 968/87. http://www.gob.gba.gov.ar /legislacion/legislacion/l-9889.html. [Fecha de consulta: 12.12.2016]. Cf. en especial artículos 14-16. 
de ello, el congreso nacional —en el cual los bonaerenses representaban un terciorecién definió la fórmula de presidente y vicepresidente de la República el 6 de septiembre de 1983 (Ferrari, 2009). De modo que cualquier pretensión de formar alianzas, si la hubo, era imposible porque se encontraba fuera de plazo.

La derrota electoral de 1983 fue traumática para el PJ ya que era la primera vez que perdía la presidencia de la Nación y la gobernación de la provincia de Buenos Aires - su principal bastión- en elecciones libres. Quedó muy bien posicionado al obtener doce gobernaciones y, con ello, el control mayoritario del Senado. No obstante, el partido transitó una profunda crisis centrada en la crítica a una conducción incapaz de proponer un proyecto a la sociedad pese a su eficacia para retener los cargos partidarios y las candidaturas. ${ }^{4}$ La fractura se clarificó a fines de 1984, en un congreso nacional partidario en el que la conducción se autoconfirmó en el gobierno. Los que tenían mayores posibilidades de revertir la situación eran los gobernadores (Ivancich, 2004), quienes, acompañados de dirigentes excluidos del armado de 1983 —entre los cuales se destacaba el histórico dirigente Antonio Cafiero, desde una línea interna fundada en 1982, el Movimiento de Unidad Solidaridad y Organización (MUSO)-, reclamaron la democratización interna del partido. En la provincia de Buenos Aires los enfrentamientos adquirieron especial gravitación. ${ }^{5}$ Los mariscales de la derrota, encabezados por el excandidato a gobernador y secretario de gobierno del Consejo Nacional Justicialista (CNJ), Herminio Iglesias, hombre de las derechas sindicales, fueron desafiados por un heterogéneo sector que comenzó a autodenominarse renovador y se proponía disputar la conducción. Demandaban elecciones internas por voto directo para elegir dirigentes partidarios y candidatos. Esta herramienta democratizadora tenía un costado instrumental, pues se esperaba que la decisión de los afiliados derivara en el reemplazo de una conducción que podía reproducir su mandato si continuaba vigente el voto indirecto.

Una sucesión de congresos partidarios nacionales y provinciales hasta mediados de 1985 dejó en claro que, pese a los esfuerzos de la ya identificada como Renovación Peronista, no sería fácil desplazar a los dirigentes que se autoconfirmaban una y otra vez (Ferrari, 2014). Cuando fue evidente que Iglesias no convocaría a elecciones directas, los renovadores presentaron una lista alternativa para las elecciones legislativas de noviembre de 1985.

Esos comicios canalizaron la interna peronista. A fin de conseguir una mejor performance electoral frente a los adversarios externos - el radicalismo- e internos - los ortodoxos - , los renovadores buscaron apoyos en fuerzas minoritarias, como

5 En aquellas provincias donde el peronismo obtuvo la gobernación fueron más moderados (Ferrari y Mellado, 2016). 
también lo hicieron los herministas. ${ }^{6}$ Unos y otros recuperaron las prácticas coalicionales pasibles de ser reconocidas incluso en la etapa formativa del peronismo, como también en las más cercanas elecciones de 1973, cuando el peronismo encabezó el Frente Justicialista de Liberación (FREJULI) junto con el Movimiento de Integración y Desarrollo (MID), el Partido Conservador Popular y el Partido Popular Cristiano - una fracción de la DC-.

La diferencia de 1985 fue que la fragmentación del PJ dio lugar a la formación de dos frentes. Iglesias organizó su FREJULI con el MID y una decena de partidos menores. Los renovadores organizaron el Frente Justicialista para la Democracia y la Participación (FREJUDEPA), pero no solo para sumar fuerzas sino también para tener la posibilidad de presentarse a elecciones, ya que necesitaban contar con personería jurídica, que dos partidos pusieron a su disposición. Uno de ellos fue su principal aliado, la DC, unificada en 1981 y conducida por entonces por Humanismo y Liberación, una línea de centroizquierda del espectro partidario (véase infra). Otra fue el Partido Renovador. A ellos se sumaban otras agrupaciones, entre las que sobresalía el Partido Popular. Una segunda diferencia respecto de 1973 fue que esos frentes pudieron organizarse solo en algunos distritos. En la provincia de Buenos Aires el FREJUDEPA llevó a Cafiero como primer diputado nacional. Llegadas las elecciones, no triunfó frente al radicalismo, que se encontraba en su mejor momento electoral, pero se impuso sobre su adversario interno.

Desde entonces la Renovación se afianzó dentro del partido y en cada elección sucesiva reeditó la práctica coalicional. Pero algo había cambiado: Cafiero afirmó que «tras el resultado electoral de 1985 todos volvían a ser peronistas, salvo Herminio», ${ }^{7}$ con lo cual los partidos minoritarios del frente eran reubicados en un rol menor. Mientras tanto, continuaba tramitándose la interna peronista. A fines de 1985 la conducción del MNJ envió a Julio Mera Figueroa a intervenir el PJ bonaerense. El cronograma electoral fue dilatado, probablemente para evitar que el triunfo renovador fuera capitalizado en lo inmediato y habilitar la emergencia de tensiones y fracturas dentro de la renovación (Ferrari, 2015). Aun así, la lista encabezada por Cafiero ganó las elecciones internas de 1986. Alcanzó la mayoría en el consejo provincial justicialista, mientras que la lista de Federalismo y Liberación —una línea nacional desembarcada con la intervención en la provincia, que respondía al gobernador riojano Carlos Menem - retuvo la minoría. Cafiero fue elegido presidente de dicho consejo. En 1987 el peronismo bonaerense lo eligió gobernador por aclamación.

En esa instancia fue organizado el Frente Justicialista Renovador (FJR), cuyos principales integrantes además del PJ eran la DC, la Unión Popular y

6 «El sector oficialista», El Día, La Plata, 19.2.1985, 4; «Asumió la junta», El Día, La Plata, 21.3.1985, 2.

7 De la entrevista a Ricardo Vago realizada por la autora en la Ciudad Autónoma de Buenos Aires el 26.7.2016. 
el Partido Conservador Popular. En la ocasión, el peronismo bonaerense explicitó su concepción algo ambigua acerca del frente. ${ }^{8}$ Se lo concebía por defecto: no era una asociación de fuerzas dispares en torno a fórmulas y programas destinados a derrotar a un adversario o a evitar el surgimiento de un movimiento popular. Un frente debía compartir una propuesta y se apeló a dos modelos: la convocatoria del general Perón cuando en su primera campaña política invitó «a quienes interpretaran su mensaje o se identificaran con él a acompañar su propuesta», y la instancia de 1973, cuando el peronismo amplió la «convocatoria generosa al Frente [que] recibe el apoyo de numerosas agrupaciones políticas». En 1983, continuaba, fue imposible repetir la experiencia porque el peronismo se encontraba debilitado, desarticulado, falto de líder y con una dirigencia deslegitimada. Le sucedieron «años duros de depuración interna» hasta el surgimiento de una figura «con autoridad legítima y convocante», la de Cafiero, que atrajo la incorporación de extrapartidarios. «Otros seis partidos acompañan al nuestro en la provincia de Buenos Aires», se afirmaba, y la experiencia, reiterada en otras provincias, anunciaba el gran frente que se activaría ante las elecciones presidenciales de 1989, conservando las banderas tradicionales del peronismo. Ese frente permitiría reunir votos para alcanzar el gobierno, distribuir cargos y promover políticas públicas. ¿Cuál era el rol de los partidos minoritarios en esa coalición? Volvían a pronunciarse por defecto: no era el de la convergencia, sinónimo de confluencia de grupos de poder e intereses, en la cual los partidos minoritarios «sacrifican su identidad a cambio de algún pequeño espacio provincial o municipal». ${ }^{9}$ Pero no se explicitaba más que la convocatoria «al Frente para el cambio, la renovación, la justicia y el bienestar, el trabajo y la dignidad a la que nos acostumbró el Gral. Perón [...]». ${ }^{10}$

El 6 de septiembre de 1987 el FJR triunfó con el 46,5\% de los votos. Su principal adversario, la UCR, obtuvo el 39,7\%. Dejó muy atrás al Frente Popular 17 de Octubre, la estertórea línea de seguidores de Iglesias, que recibió la adhesión del MID, el Partido Conservador Autonomista y la Alianza Patriótica (Ferrari, 2014). Y Cafiero ganó la gobernación.

En enero de 1988 el flamante gobernador fue consagrado presidente del CNJ. Se encontraba en el cenit de su poder, lo que auguraba su candidatura presidencial,

«Frente Nacional o convergencia personal», en Partido Justicialista de la provincia de Buenos Aires, Boletín n. ${ }^{\circ}$. Julio de 1987, segunda quincena, 2-3. En 1987 integraban el frente que sostuvo la candidatura a gobernador de Cafiero, además del PJ, el PDC, el Partido de la Izquierda Nacional, el Partido Conservador Popular, el Partido Socialista Auténtico, el Partido Renovador y la Confederación Socialista.

9 Esto era un tiro por elevación al radicalismo, dado que el presidente Raúl Alfonsín había convocado a la convergencia con la esperanza de pactar apoyos para aprobar sus proyectos en el parlamento. Cf. Martín Prieto, "Alfonsín convoca a una "convergencia democrática" en Argentina», El País, Madrid, 4.8.1986. http://elpais.com/diario/1986/10/04/internacional/528764429_850215.html [Consultado el 13.5.2016]. 
cuando una serie de razones - resultado de la mediación del interventor, la febril acción de los renovadores opositores encabezados por Eduardo Duhalde (Ferrari, 2013), el carisma y la habilidad política del adversario interno, entre otras - confluyeron para que, a mediados de 1988, Cafiero perdiera las internas frente a Menem, aun en su distrito. La derrota colocó un tope a su trayectoria política, fue un golpe para la Renovación Peronista e introdujo realineamientos en los socios de la coalición electoral. Como se verá, Humanismo y Liberación, el sector de la DC más favorable a la formación de un frente con el cafierismo, decidió no volver a aliarse con el PJ y la mayoría de sus miembros se separó del tronco partidario.

Para las elecciones nacionales de 1989 se reiteró la práctica coalicional. El Frente Justicialista de la Unidad Popular (FREJUPO) recibió el apoyo de nuevos integrantes. Tras el PJ se encolumnaron dos viejos aliados, la DC francamente disminuida y el PSA, a los que se sumaron el PI, el Partido del Trabajo y el Pueblo (comunismo revolucionario) y el Movimiento Patriótico de Liberación de Jorge Abelardo Ramos, de aires trotskistas. Eran partidos ubicados en el espectro de la izquierda y la centroizquierda. La propuesta de Menem, centrada en la promesa de salariazo y la revolución productiva, recibió el apoyo de la mayoría de la población en un clima signado por los fracasos económicos y también políticos del alfonsinismo. La presidencia quedó en manos del justicialismo.

Una nueva convocatoria electoral tuvo lugar en 1991, para definir parlamentarios, legisladores y la gobernación de la provincia de Buenos Aires. El giro neoliberal introducido por el menemismo en materia económica y, muy especialmente, los decretos de indulto a los militares juzgados durante el alfonsinismo provocaron realineamientos. Así como el oficialismo obtuvo la adhesión de la centroderecha, algunas fracciones se alejaron del frente. Del propio PJ se escindió el llamado Grupo de los Ocho.11 Junto con otros partidos minoritarios confluyó en experiencias - tales como el Movimiento por la Democracia y la Justicia Social (MODEJUSO), que luego adoptó el nombre de Frente por la Democracia y la Justicia Social (FREDEJUSO) - que posteriormente derivaron en el Frente Grande (Novaro y Palermo, 1998: 81-96). También se escindió una fracción conducida por el ex secretario general de la CGT, Saúl Ubaldini. Aun así, el tronco del PJ y los oficialismos de los partidos minoritarios volvieron a coincidir en una alianza electoral.

11 El Grupo de los Ocho fue la denominación atribuida por la prensa a una fracción de diputados nacionales del PJ que se desprendió del tronco partidario en 1989. Las causas que desencadenaron ese desprendimiento fueron la oposición a las reformas económicas estructurales de corte neoliberal y, muy especialmente, a los indultos a los militares procesados por haber participado en el terrorismo de Estado y a los amotinados en Semana Santa de 1987. Ese bloque parlamentario independiente era integrado por Germán Abdala, Darío Alessandro, Carlos Chacho Álvarez, Luis Brunati, Juan Pablo Cafiero, Franco Caviglia, Moisés Fontela y José Ramos. Todos habían formado parte de la Renovación peronista, de la que constituían el grupo más radicalizado. 
En la provincia de Buenos Aires, el peronismo se encontraba organizado en dos ligas: la Liga Federal del entonces vicepresidente de la República, Eduardo Duhalde, y la Liga Peronista Bonaerense (LIPEBo), que seguía al aún gobernador Cafiero derrotado también en su intento de reformar la constitución provincial一, sin fuerzas para imponer un sucesor. Duhalde aceptó la candidatura por ofrecimiento de Menem una vez asegurado un fuerte apoyo económico y el de los intendentes peronistas bonaerenses (Ferrari, 2013). Se autoproclamó «peronista biológico» para distanciarse del rumbo neoliberal adoptado por el gobierno nacional. Tras realizar elecciones internas de las que resultó electa la fórmula Duhalde-Rafael Romá, el PJ volvió a aliarse con una debilitada DC en el Frente Justicialista Federal (FREJUFE); pero, a diferencia de lo ocurrido en el orden nacional en 1989, no recibió el apoyo del PI. Y volvió a ganar las elecciones.

\section{La centroizquierda en los frentes peronistas de los años ochenta}

Como se observó, la DC y el PI integraron alianzas electorales con el PJ durante la década de 1980. Ambos partidos reconocían tradiciones diferentes y habían mantenido vínculos también distintos con el PJ. La DC era un partido no confesional de matriz cristiana (Cerro, 1983), que evolucionó de grupos católicos que se oponían fuertemente al peronismo de mediados de siglo. Algún tiempo después de la fundación del partido en 1958, en la DC latinoamericana se produjo un giro favorable a los movimientos populares y nacionales (Mainwaring y Scully, 2010), que derivó en la apertura hacia agrupaciones estudiantiles, sindicatos, partidos políticos y en la composición de alianzas. En Argentina esto se tradujo en un acercamiento al justicialismo, posible de observar, por ejemplo, en el intento frustrado de proponer a Raúl Matera como integrante de la fórmula presidencial democristiana en 1963. La coalición recién se plasmó en 1973, cuando una de las fracciones originadas del partido madre, el Partido Popular Cristiano, se sumó al FREJULI, desde donde sus representantes alcanzaron cargos legislativos, nacionales y provinciales (Cerro, 1983; Ghirardi, 1983). ${ }^{12}$ Tras la muerte de Perón, cuando el tumultuoso peronismo se dividió entre verticalistas y antiverticalistas (Ferrari y Pozzoni, 2014), la conducción democristiana se alineó con los segundos, opuestos al gobierno de la viuda de Perón. ${ }^{13}$ Pero hacia fines de 1975, cuando

12 La otra fracción, el Partido Revolucionario Cristiano, encabezado por Horacio Sueldo, junto con el PI, el PC y sectores de UDELPA, integró la Alianza Popular Revolucionaria, desde donde también accedió a cargos electivos de gobierno.

13 En un contexto de creciente violencia política y de crisis generalizada, el PPC conducido por Carlos Auyero en el Congreso nacional participó activamente en una escisión protagonizada por 40 parlamentarios 
era previsible su derrocamiento, los dos partidos democristianos retomaron el diálogo. Ya en dictadura, y pese a los conflictos internos en que se vieron sumidos los democristianos debido al posicionamiento, dialoguista o intransigente, asumido ante el régimen militar (Ferrari, 2017), la fusión se logró en 1981. Internamente permanecieron distintas líneas, de las cuales la más progresista era Humanismo y Liberación (HyL). Por entonces el partido, y en especial la mencionada línea, se identificaba en una lucha comprometida con los sectores populares, trabajadores y pobres, y los cambios revolucionarios sin violencia inspirados en Juan Pablo II y Juan XXIII (Vicente, 1981: 178-181).

Por su parte, el PI, que se definió como tal en 1972, era heredero de la larga trayectoria de la intransigencia radical que se reconocía en el alemnismo, se prolongaba en el yrigoyenismo de matriz nacional, popular y antioligárquica también presente en la Fuerza de Orientación Radical de la Joven Argentina (FORJA) (Nosiglia, 1983) y en el Movimiento de Intransigencia y Renovación (MIR). ${ }^{14}$ Tres hitos signaron la trayectoria de este partido: la escisión de la UCRP en 1957, que llevó a quienes continuaron en el partido a definirse como intransigentes y formar la UCRI; la separación del frondizismo que constituyó el MIR, fugaz antecedente del MID, a raíz de las negociaciones con el peronismo en 1963, y las disposiciones de 1972 que, ante la apertura democrática, conservaron la designación de radicales para la UCRP, lo que llevó al sector cuyo referente era Oscar Alende a definir a su fracción como PI. Alende fue el líder indiscutido de este partido hasta su muerte. En 1973 se presentó a elecciones encabezando la fórmula sostenida por la Alianza Popular Revolucionaria (APR), una coalición formada por el PI, el Partido Comunista, el Partido Revolucionario Cristiano - el otro desprendimiento de la DC encabezado por Horacio Sueldo- y algunos sectores de la Unión del Pueblo Argentino (UDELPA). En uno de los documentos orgánicos del partido, el PI se posicionaba a favor de la liberación y se reconocía revolucionario; destacaba la matriz movimientista y popular del yrigoyenismo y el peronismo que confluirían en el tercer movimiento histórico del cual el PI formaría parte. ${ }^{15}$ De manera que, aunque no integrara el FREJULI, el PI reconocía cierto parentesco con el PJ.

En 1981 la UCR convocó al PJ, la DC, el PI y el MID a integrar la Multipartidaria, que, lejos de ser un frente electoral, ofrecía un marco de acuerdos mínimos a la salida de la dictadura. ${ }^{16}$ En vísperas de las elecciones del 10 de octubre de 1983, los candidatos

-27 de ellos bonaerenses, de los cuales 25 eran justicialistas y 2, populares cristianos -, que se constituyeron como «FREJULI-Grupo de Trabajo». Por su número, este bloque — del cual Auyero ocupó la vicepresidencia - se transformó en la segunda minoría en la Cámara, después del radicalismo.

14 Lo integraban, entre otros, Moisés Lebensohn, Francisco Ratto, Crisólogo Larralde, Ricardo Balbín, Francisco Rabanal, Oscar Alende, Arturo Frondizi y Carlos Rabanaque Caballero (Nosiglia, 1983).

15 Cf. «Aportes para un proyecto nacional», 1975.

16 Cf. Documento del Comité Nacional del PI, 3.7.1982, p. 7. CEDINCI, Col. Volantes. Carpeta 29-PI (19822003). 
presidenciales de los cinco partidos de la coalición firmaron la Carta Democrática, en la que se comprometían a defender la Constitución y el sistema democrático, garantizar el proceso constitucional, establecer como cuestiones fundamentales la defensa de las personas y los derechos humanos y buscar espacios de coincidencia ante problemas futuros; ${ }^{17}$ es decir, a dar continuidad a la institucionalidad y la vida democrática y dejar abiertas las puertas hacia las coincidencias entre partidos. Algunas de estas derivaron en la conformación de frentes ¿Cómo participaron de ellas la DC y el PI y en qué condiciones acompañaron al dinámico peronismo? ¿Qué consecuencias derivaron de ello?

\section{La Democracia Cristiana}

A la salida de la dictadura la DC era un semillero de individualidades (Wynarcyk, 2010). En 1983 alcanzaba los 65.894 afiliados (Parera, 1986: 408). La imposibilidad de constituir un frente con el peronismo era evidente, y no solo por cuestión de plazos. El PJ, conducido por el sector más ortodoxo, algunos de cuyos integrantes manifestaban su proximidad con referentes de la dictadura militar, no era un aliado posible para un partido que llevaba como bandera la defensa de los derechos humanos. En efecto, numerosos dirigentes de HyL integraban los organismos de derechos humanos (Vicente, 2006). El único diputado nacional que consagró la DC en esas elecciones fue Augusto Conte, padre de un desaparecido y uno de los fundadores del Centro de Estudios Legales y Sociales, quien se presentó a elecciones como el candidato de los derechos humanos y pidió explicaciones a Iglesias cuando este alardeaba de su amistad con los militares represores.

Solo cuando un sector del peronismo asumió críticamente la democratización y cuando en 1985 HyL ganó la interna partidaria, la DC se alió con la fracción cafierista de la Renovación. Numerosas cuestiones los aproximaban. Entre las de largo plazo, la matriz humanista cristiana, la pertenencia al movimiento nacional y popular, la coincidencia doctrinaria y de apreciación del proceso político, económico y social, la convergencia alrededor de las viejas banderas de liberación nacional, justicia social y soberanía popular, y aun el reconocimiento al liderazgo popular de Perón. ${ }^{18}$ Entre las coyunturales, en 1985 existían liderazgos claros, legales y legitimados, capaces de propiciar el vínculo entre ambos partidos: Cafiero por el PJ y Carlos Auyero por la DC.

Carta Democrática, Buenos Aires, 27.10.1983. Libro de Actas, ADC. Firmaron los cinco candidatos presidenciales y un sinnúmero de afiliados.

18 Hacha y Tiza, «Editorial», año I, n. ${ }^{\circ}$ 1, octubre de 1984, 3-4. El director de esta publicación partidaria, Víctor Sonego, integrante de Humanismo y Liberación, se pronunció a favor del Movimiento Nacional y Popular. 
Pero también era nítido el acercamiento de dirigentes intermedios, algunos de los cuales se habían prolongado durante la dictadura militar. ${ }^{19}$ Algunos de ellos alentaban la formación de un frente entre el PJ y la DC que aportaría el respeto a la persona y la libertad, propio de los valores cristianos del pensamiento nacional. ${ }^{20}$

No fue posible una alianza en todos los distritos. En Capital Federal la DC se encontraba sumida en una crisis que derivó en la intervención partidaria, demoró la convocatoria de la convención e impidió concretar la coalición. ${ }^{21}$ Pero en la provincia de Buenos Aires la interna democristiana se resolvió sin mayores conflictos y en agosto de 1985 se decidió integrar un frente con los renovadores. El 6 de septiembre quedó conformado Frente Renovador en un acto celebrado en la Capital Federal, donde Auyero resaltó la convergencia doctrinaria y de apreciación del proceso político, económico y social del PJ renovador y la DC, como también la defensa de la democracia, la justicia social y la lucha por la liberación nacional. ${ }^{22}$

La formación del frente tuvo costos y beneficios para el socio minoritario. Los primeros se tradujeron en fuertes tensiones al discutirse los espacios asignados a los democristianos en las listas de candidatos. Por considerar que a la DC debían corresponderle más candidaturas posibles de ser electas en la lista, Horacio Sueldo, extrapartidario, primer candidato a diputado nacional por la DC y tercero en las listas del Frente, renunció. Cuestionaba que los peronistas ocuparan la amplísima mayoría de cargos de diputados nacionales, mientras solo el tercero y el decimocuarto lugar se habían reservado a la DC y el duodécimo al Partido Renovador. ${ }^{23}$ La renuncia de Sueldo traducía un descontento que los peronistas subestimaban como tironeos previos al armado de las listas. ${ }^{24}$ Impactó en cuestionamientos a la conducción de Auyero, acusado de ponderar el vínculo con el peronismo sobre la defensa del partido. Este se vio obligado a dejar su candidatura en Capital Federal para ocupar la vacante dejada por Sueldo ${ }^{25}$ y a explicitar los beneficios prácticos que obtendría la DC de continuar en el Frente: un diputado nacional, otro provincial, entre 20 y 25 concejales y otros tantos

Los seminarios fueron convocados a partir de 1977 desde la fundación FAPEs. En 1979 algunos dirigentes democristianos y peronistas confluyeron en el Club Nacional. Cf. Ferrari, 2017.

20 Alicia Anda, «Hay plafón para un peronismo renovado». Reportaje a Julio Bárbaro. Hacha y Tiza, año I, n. ${ }^{\circ}$ 1, octubre de 1984, 19-21.

21 «Buscan un acuerdo en la Democracia Cristiana metropolitana», Clarín, Buenos Aires, 18.7.1985, 7.

22 Expresiones de H. Sueldo y A. Cafiero, «Presentación del Frente Renovador», Clarín, Buenos Aires, 7.9.1985, 2. «Querella de Cafiero contra Iglesias», El Día, La Plata, 7.9.85, 3.

23 «Herminio Iglesias encabeza la nómina del Frejuli en la Provincia», El Día, La Plata, 14.9.85, 3. Las listas de legisladores provinciales siempre fueron encabezadas por peronistas y solo en la 3 a $^{\text {a }}$ sección el democristiano Alberto Aramouni ocupó el segundo lugar.

24 Expresiones de Luis Macaya, «Descartan fractura en el sector cafierista», Clarín, Buenos Aires, 13.9.1985, 12. 
consejeros escolares. ${ }^{26}$ Aunque a la luz de los resultados electorales de noviembre de 1985 no se equivocó, las tensiones entre los democristianos salieron a la luz.

Pasados los comicios la alianza se tradujo en la distribución de cargos, pero no necesariamente en acciones de gobierno conjuntas, tal como ocurrió en la Cámara de Diputados durante la sanción de las leyes de Punto Final (1986) y Obediencia Debida (1987). ${ }^{27}$ Esto fue particularmente sensible para los democristianos que asumían la defensa de los derechos humanos, tal como había quedado demostrado no solo en la elección de Conte en 1983 y de su reemplazante, Ángel Bruno, en 1985, sino también en el cierre de campaña del Frente Renovador en 1985, donde Auyero exigió juicio y castigo a los culpables de violaciones a los derechos humanos, ${ }^{28}$ tema incluido en el programa del Frente. Tampoco hubo respuestas unánimes respecto de las posiciones sostenidas por el bloque democristiano con respecto al blanqueo de capitales, las privatizaciones y el llamado presidencial a la convergencia impulsados por Augusto Conte, o la Ley de Entidades Financieras presentada por Carlos Auyero. ${ }^{29}$ Es decir, el Frente tuvo los resultados esperados por la DC como coalición electoral, pero funcionó desajustadamente como coalición de gobierno.

Aun así, la DC reeditó la experiencia. Ante las elecciones de 1987, alertados por las tensiones precedentes, el candidato con más posibilidades de integrar la lista de diputados nacionales por la provincia de Buenos Aires, Alberto Aramouni -legislador bonaerense y vicepresidente segundo de la conducción nacional—, afirmó que el frente electoral con el peronismo renovador se llevaría a cabo si los candidatos de su partido ocuparan lugares con posibilidad de asegurar su elección en las listas. Solo así los hombres de la DC comprometerían sus esfuerzos para confrontar con el proyecto liberal y de resignación de la UCR. ${ }^{30}$ Las tensiones se mantuvieron hasta el último día de presentación de listas, a tal punto que la DC amenazó con presentar sus propios candidatos a gobernador bonaerense. ${ }^{31}$ Finalmente, el Frente Renovador integrado por el PJ, la DC, el Partido de la Izquierda Nacional, la Confederación Socialista y el Partido Socialista Auténtico cerró su lista de diputados nacionales en la que participaron dos

«Situación en la Democracia Cristiana», Clarín, Buenos Aires, 18.9.1985, 11.

27 «El voto del otro Congreso», Clarín, 3.2.1998, http://edant.clarin.com/diario/1998/02/03/t00601d.htm (consultado el 18.7.2016). El conjunto de la DC expresó su desagrado ante el proyecto de ley de Punto Final, el llamamiento a los legisladores nacionales para que rechazasen el proyecto y la convocatoria a movilización. Junta Ejecutiva del PDC de la Capital Federal, «Declaración». s/f, ADC. Junta Nacional, «El PDC y el proyecto de ley de "punto final”», comunicado de prensa, 13.12.1986, ADC.

28 «Multitudinario acto de clausura de Antonio Cafiero», Clarín, Buenos Aires, 1.11.1985, 5.

29 «Posiciones. Bloque Demócrata Cristiano de la Cámara de Diputados de la Nación». Buenos Aires, octubre de 1986.

30 «Acuerdo renovador con demócratas [sic] cristianos». Crónica, 14.1.1987, p. 9. Se consideraba que Aramouni ocuparía el $12 .^{\circ}$ o $13 .^{\circ}$ puesto, mientras que Eduardo González, presidente del Comité provincial de la DC, integraría la lista a título simbólico, sin posibilidades de acceder a ningún cargo. 
democristianos: Aramouni en el 10. lugar y Eduardo González en el $17 .^{\circ}$ —sin posibilidades de ingreso-.

A las diferencias siempre existentes entre las fracciones de la DC se sumó la alternativa de seguir formando frentes con el peronismo cuando Menem triunfó como candidato presidencial en la interna de su partido. Se puso en evidencia que el acuerdo era entre Auyero y Cafiero, porque la fracción de HyL que había encabezado la propuesta aliancista se desprendió del tronco partidario y organizó una nueva fuerza política conducida por aquel. El nuevo partido se autorrepresentó como «un frente social», «un espacio popular de centro-izquierda» con vocación federal, reclamado por los ciudadanos progresistas provenientes de los sectores populares y medios de la sociedad «ante un sistema político que se estabiliza con un alto grado de exclusión y distorsión de las demandas sociales, y partidos que tienden estructuralmente a la indiferenciación por derecha con una creciente subordinación a poderes de facto y permeabilidad a la ofensiva neoliberal». ${ }^{32}$ Los diputados nacionales que suscribieron ese proyecto informaron que el bloque integrado por Carlos Auyero, Matilde Quarraccino y Alberto Aramouni adoptaría el nombre de Democracia Popular. Desde allí se opusieron a las leyes de Reforma del Estado y de Emergencia Económica. ${ }^{33}$ Pronto recuperaron su tradición frentista: con el Grupo de los 8 nutrieron el MODEJUSO, el FREDEJUSO y posteriormente el Frente Grande y la Alianza.

Quienes permanecieron en la DC repudiaron la escisión desde el frente político y el sindical, ${ }^{34}$ pero se manifestaron contrariados por el desapego manifiesto del gobierno respecto de la plataforma acordada y la falta de convocatoria a los integrantes del Frente para decidir políticas. Aun así se mantuvieron en el FREJUPO ${ }^{35}$ y declararon su

32 Se declaraba su vocación federal cuando se proponía incluir las realidades provinciales a fin de vertebrar y potenciar al conjunto. Los principios que orientaban la iniciativa eran: profundizar la democracia como requisito de su consolidación y condición de posibilidad en todos los planos de la vida social; devolver la iniciativa al pueblo; socializar el poder; defender integralmente la vigencia de los derechos humanos y la dignidad de la persona; rescatar la utopía de una comunidad igualitaria y liberadora; fortalecer el sentido de comunidad; sustantivar un proyecto no estatista de transformación democrática que comience a gestarse en la sociedad y desde ella a través de diversas formas asociativas de propiedad social, cooperativas de trabajo y experiencias de autogestión; postular un Estado activo en la regulación y en la planificación; descentralizar y desburocratizar el aparato estatal mediante estructuras comunitarias de participación, gestión y propiedad; defender la identidad cultural y el protagonismo de los pueblos latinoamericanos en la consolidación de su unidad definitiva. «Hacia un proyecto abierto. Comisión promotora, septiembre de 1989», en Democracia Popular por el Frente Social, Aportes para el debate del proyecto. Diciembre de 1989, s/e, s/l, pp. 11 y 12.

33 Cf. la entrevista a Carlos Auyero en https://www.youtube.com/watch?v=Qqe39SzOjro\&feature= youtu.be\&a $=$ [Fecha de consulta: 2.8.2016].

34 El Movimiento de Trabajadores Demócrata Cristianos (MTDC) mantuvo un comportamiento orgánico («dentro del partido, todo; fuera del partido, nada»). Repudió lo que calificaba como falta de espíritu pluralista y democrático. Nota del MTDC de la provincia de Buenos Aires, septiembre de 1989. Carpeta Notas Recibidas. Archivo DC. «Riesgo de disgregación». Diario Popular, Buenos Aires, 25.2.1990. 
propósito de luchar en el cumplimiento del programa votado el 14 de mayo de $1989 .{ }^{36}$ Los democristianos bonaerenses declaraban su coincidencia con la reforma del Estado - por ejemplo, con la racionalización ferroviaria en el marco de la búsqueda de eficiencia- ${ }^{37}$ Pero criticaban que dicha reforma estuviera asentada «sobre criterios neoliberales que implementan una estructura de corte capitalista ajena al movimiento nacional y popular». ${ }^{38}$ Defendían el rol intervencionista del Estado en economía tomando el ejemplo de los países centrales para favorecer «el crecimiento y bienestar armónico de todos sus integrantes». No admitían que en una sociedad basada en la justicia y la equidad se desarticularan esas funciones. Y, a modo de advertencia, afirmaban que la DC «solo está atada —en sus decisiones y compromisos - a la coherencia con su doctrina y los acuerdos pactados con la constitución de los frentes políticos y electorales que ha integrado»; en consecuencia, «no aprueba ninguna política que tienda a incrementar la desocupación o utilización del salario como variable de ajuste» y se opondrían «tenazmente a toda política de flexibilización o desregulación laboral».39

Desde la DC se sucedieron las denuncias sobre los efectos devastadores de la política económica liberal sobre los asalariados, las medidas políticas «dictadas por los que obtuvieron solo el $9 \%$ de los votos en las últimas elecciones y las imposiciones del FMI» ${ }^{40}$ y las privatizaciones monopólicas. ${ }^{41}$ Eran criticados los indultos como peligrosos para la democracia y se denunciaban rumores sobre el retorno de la doctrina de seguridad nacional. ${ }^{42}$ Se consideraba menester que el gobierno estuviera alerta ante las corporaciones y comprendiera que su base de apoyo era el pueblo que lo había votado. ${ }^{43}$ Estos pronunciamientos eran sucedidos por acciones tales como una jornada

36 Nota por la que se ratifica la pertenencia al FREJUPO, Buenos Aires, 19.12.1989. ADC.

37 Declaración de la Junta Ejecutiva de la DC metropolitana. Asunto: decretos de racionalización ferroviaria. Buenos Aires, enero de 1990. ADC. Nota de la Secretaría de Asuntos Municipales de la Junta Ejecutiva de Capital Federal, enero de 1990, ADC.

38 «Preocupa a los democristianos el rumbo socioeconómico del país». La Prensa, 3.11.1989; del documento de la DC bonaerense, firmado por Roberto Vallejos, presidente del partido.

39 Ibídem.

40 Declaración de la Junta Ejecutiva, Buenos Aires, 7.2.1990. Recibida por la Agencia Noticias Argentinas. ADC.

41 «El rol del Estado. Hacer posible lo necesario». Documento de prensa, Junta Capital, 29.3.1990. Sintetiza la postura del bloque DC durante la interpelación al ministro de Obras Públicas, Roberto Dromi. Extractos de la intervención de Eduardo González y «Declaración de la Junta Ejecutiva de la Capital Federal», Buenos Aires, 14.3.1990. ADC.

42 Declaración de la Junta Ejecutiva de Capital Federal. Buenos Aires, 7.12.1989. ADC. Declaración de la Junta Ejecutiva Metropolitana. Buenos Aires, 27 de diciembre de 1989. ADC. Véase asimismo «La DC alerta sobre enfrentamientos». El Cronista, 25.2.1990, p. 7.

43 Declaración de la Junta Ejecutiva de Capital Federal. Buenos Aires, 7.12.1989. ADC. 
de reflexión sobre derechos humanos o el reclamo de soluciones a carencias estructurales. ${ }^{44}$

Pero ni las instancias de discusión sobre las políticas nacionales con el resto de los integrantes del FREJUPO, ${ }^{45}$ ni las amenazas de expulsión del partido al ministro de Economía de origen democristiano, Erman González, ${ }^{46}$ ni la propuesta de las autoridades nacionales partidarias para convertir los espacios que la DC ocupaba en el frente en puestos de combate para que el proyecto nacional no sucumbiera, ni el reclamo de una «concertación a las fuerzas políticas, sociales, del trabajo y la producción [para] canalizar el protagonismo popular, que es el mejor reaseguro para la estabilidad ${ }^{47}$ impactaron sobre el gobierno nacional. El frente, eficiente como herramienta electoral, no fue una coalición de gobierno en la que se tuviera en cuenta el programa acordado.

\section{El PI en el Frente Justicialista de Unidad Popular}

La discusión acerca de la formación de alianzas en el PI fue un tema recurrente. A la salida de la dictadura, el partido se autorrepresentaba como una fuerza con voluntad de forjar una democracia que superara la mera institucionalidad, en consonancia con la tradición revolucionaria nacional, popular y antiimperialista que asumía. ${ }^{48}$ Internamente, se reconocían diferentes líneas que variaban según el distrito, pero en conjunto reclamaban para el partido la representación de la izquierda democrática. Entre las más extendidas se encontraban la VTR (sigla que remitía al viejo tronco radical), formada por los seguidores históricos de Oscar Alende; en Capital Federal también se encontraba la llamada Lista Verde, de Raúl Rabanaque Caballero. Pero si por algo se destacaba el PI era por contar con una vigorosa juventud fraguada al calor de la recuperación democrática, con proyección nacional. Algunos de esos jóvenes contaban con experiencia militante (Marcelo Vensentini en el PRT; Martín Farisano en

44 Reflexión pública sobre derechos humanos. Buenos Aires, 7.12.1989. ADC. Declaración de la Junta Ejecutiva de Capital Federal. Buenos Aires, 20.12.1989. ADC.

45 «AA dónde va el país?». Convocatoria de partidos integrantes del FREJUPO. s/f, ADC. Por el PJ participaron los referentes del Grupo de los Ocho, Chacho Álvarez y Germán Abdala; por el PI, Eugenio Semino; por la DC, Ángel Bruno, presidente de la Junta Capital; Jorge Selser por el PSA y Antonio Caporale por el PCTendencia nacional. Cf. otra convocatoria en «Un año en la otra vereda», Página 12, 13.5.1990. «El FREJUPO enfrenta la política del gobierno», El cronista, 13.5.1990. El FREJUPO se siente defraudado». Sur, 13.5.1990.

46 «Advertencia democristiana a Antonio Erman González». La Nación, 22.2.1990. Declaración de la Junta Ejecutiva de Capital Federal, 21.2.1990. ADC.

47 «Crítica y denuncia de la DC». Clarín, 18.2.1990. Por entonces la Junta Nacional era presidida por el correntino Esio Silveira; la Secretaría General era ocupada por Otelo Zamponi.

48 Documento del Comité Nacional del Partido Intransigente, Buenos Aires, 3.7.1982. CEDiNCI, Col. Volantes. Carpeta 29-PI (1982-2003). 
Montoneros; Armando Ledesma en la izquierda peronista no militarizada); pero, por razones de edad, por el impedimento que significó la dictadura, por el exilio propio o de sus padres, mayoritariamente se forjaron en política durante la coyuntura. ${ }^{49}$ Entre los grupos juveniles más reconocidos se encontraba La Banda de Capital Federal, cuyos integrantes de sectores medios acomodados tenían militancia en centros de estudiantes de colegios secundarios y en universidades (Marcos Novaro, Gabriel Puriccelli, Gerardo Aboy Carlés). Rápidamente encontraron afinidades en distintos puntos del país. En Lomas de Zamora se vincularon con el Chino Navarro, proveniente de Montoneros; en Córdoba con Horacio Viqueira, del guevarismo; en Rosario con Graciela Rocchi, de la carrera de Ciencia Política de la UNR. Los jóvenes fusionaron tradiciones políticas hasta encontrar una lingua franca que se transmutó en el léxico de los plenarios y los documentos emitidos. También ganaron la calle.

Ante la apertura democrática el PI consagró la candidatura de Oscar Alende y Lisandro Viale para la fórmula presidencial y redactó una plataforma electoral sobre la base del programa sancionado en Córdoba en $1975,{ }^{50}$ al que se reconocía la plena vigencia de su concepción democrática y revolucionaria. ${ }^{51}$ El partido se lanzó a la campaña realizando una fuerte inversión en procura de afiliados; en septiembre contaba con 73.866 (Parera, 1986: 408), elevó un programa político institucional en el que se reiteraba el objetivo de construir un modelo de democracia nacional, popular y revolucionaria; orientada por un Estado con finalidades indelegables en cuanto a la organización política, económica y social; capaz de desmontar el aparato represivo e impulsar el respeto irrestricto de los derechos humanos, impulsar formas institucionales que asegurasen la participación y el control popular (revocatoria de mandatos, derecho a la iniciativa, veto popular, plebiscito, referéndum), de manera que los grandes problemas de la vida social fueran resueltos por el conjunto de la población. En el orden económico postulaba «arrancar de manos de las minorías dominantes los factores del poder real, con planificación rigurosa del empleo de recursos naturales y financieros» en función de los objetivos nacionales y no de los monopolios internacionales ni de las oligarquías nativas. En tal sentido alentaba desvincular el sistema financiero del mercado de divisas, nacionalizar el comercio exterior, instrumentar una política financiera favorable al crecimiento económico y la socialización de la riqueza — con nacionalización de la banca y orientación del crédito-, reordenar el sector público, refinanciar la deuda externa y conseguir una moratoria, reducir la inflación y eliminar la indexación. Esto suponía transformar el Estado, democratizar el poder económico hacia el crecimiento y la defensa de los intereses populares. Proponía una

49 De la entrevista a Gabriel Puriccelli realizada por la autora en Buenos Aires, el 23 de agosto de 2016.

$50 \quad$ PI, Aportes para el proyecto nacional, 1983 [1975].

51 PI, Plataforma electoral 1983. Para que todo cambie, s/e, s/l. 
sociedad libre, justa y fortalecida, dimensionada a escala humana, que posibilitase la realización de cada individuo. Se manifestaba antioligárquico y antiimperialista. ${ }^{52}$

El 30 de octubre de 1983 la fórmula intransigente de la provincia de Buenos Aires obtuvo el 4,17\% de los votos en elecciones de gobernador. Al igual que en el conjunto del país, ocupó el lugar de una lejana tercera fuerza. ${ }^{53}$ Pero más que por su gravitación electoral el PI era importante porque ocupaba los espacios vacíos dejados por el peronismo antes de la renovación y, tras el anuncio de la «economía de guerra», la sanción del plan austral y el Punto final, por la UCR. También aglutinaba a la izquierda, dado el desprestigio que le valió al PC su apoyo al golpe de 1976. Esto se tradujo en el crecimiento del padrón de afiliados, ostensible en Córdoba, Entre Ríos, Buenos Aires, Capital Federal, Tierra del Fuego y Santa Cruz. ${ }^{54}$

La participación en coaliciones no era novedosa para el PI, que en 1973 había integrado la APR. Ya en 1984 su convención nacional propuso una política de unidad popular para la liberación como forma de defender y profundizar el sistema democrático. Plantearon formar frentes de masas — barriales, sindicales, universitarios, etc.y posteriormente generar alianzas entre ellos con la superestructura política. ${ }^{55}$ Luego de las elecciones del 3 de noviembre de 1985 en provincia de Buenos Aires corrían rumores acerca de la formación de un frente entre el PI y el PJ renovador con vistas a los comicios de 1987, fundados en cálculos electorales que, de reiterarse los resultados de las legislativas previas, aconsejaban sumar fuerzas. ${ }^{56}$ Los dirigentes bonaerenses del VTR entablaron conversaciones con el peronismo, más en virtud de futuros cargos a obtener que de acuerdos programáticos. ${ }^{57}$ Ante ello algunos cuadros de la juventud y dirigentes autodefinidos como progresistas, sin desechar la concreción de un frente electoral, plantearon que las alianzas surgieran de acuerdos programáticos serios. Abogaban por un perfil propio del PI, encaminado a modernizar el estilo político y a gestar un frente de liberación nacional y social.

En abril de 1986 la convención nacional fijó la estrategia de impulsar la creación de un frente de liberación nacional y social (FLNS) y ratificó que se llevaría a cabo «una

«Todos juntos», volante de campaña 1983. http://andytow.com/atlas/totalpais/buenosaires/1983g.html. «El crecimiento del PI», reportaje a Mariano Lorences. Intransigencia para la liberación nacional, segunda época, n. ${ }^{\circ}$ 1, septiembre de 1986, p. 8.

Honorable Convención Nacional, Documentos, Rosario, 29 de junio de 1984. Cf. http://www.pi.org.ar/ home. html [Fecha de consulta: 29.8.2016].

Aproximadamente el Frente Renovador había obtenido 1.500 .000 votos, el FREJULI 500.000 y el PI, que llevó a Alende como primer candidato a diputado nacional, 570.000. El radicalismo reunió 2.300.000. De existir una fusión de los tres primeros, quedaría comprometida la mayoría radical. José Antonio Díaz, «El pi bonaerense y las alianzas». La Razón, 9.3.1986.

Entre ellos, el titular del comité del distrito, Ricardo Balbi; el secretario de Organización, Alberto Crosetti, Orestes Introna, de Morón; el legislador Isidro Barkidjian, Matanza, 3.a, Marcelo Arabolaza; Emilio Franchi (Vicente López) y José Epelboim (Avellaneda). Ibídem. 
política de masas amplia» en los frentes de trabajo. Se perfilaron dos grandes tendencias internas. La primera, formada por quienes querían entablar tratativas con el virtual candidato a gobernador por el peronismo renovador, Antonio Cafiero, cobró tal magnitud que obligó a las autoridades partidarias a frenar el impulso para preservar la identidad electoral partidaria. ${ }^{58}$ La segunda, a la izquierda de la anterior, era integrada por militantes y dirigentes que planteaban la necesidad de constituir el FLNS dejando de lado actitudes oportunistas y electorales y priorizando la reconstrucción del campo popular. ${ }^{59}$

Recién en noviembre de 1986 se llevó a cabo el I Encuentro Nacional Intransigentes por el Frente, copado por el segundo grupo. Participaron representantes de distintas regiones del país aportando sus experiencias y se recibieron adhesiones de varios partidos. ${ }^{60}$ Se elaboró un documento en el cual se concebía al frente como herramienta de lucha para transformar las estructuras económicas del país dependiente, superar el estado de atomización del campo popular y ofrecer una alternativa al alfonsinismo. Pero este frente social no era una alianza electoral, a la que calificaban como «medio mal entendido por el aparatismo partidario a fin de obtener espacios dentro del marco de la democracia formal restringido», sino un frente estratégico de liberación nacional «al que la política de alianzas deberá estar subordinada en la táctica».61 Suponía un acuerdo programático que aglutinara la experiencia obtenida en los frentes gremial, universitario, territorial, barrial y de derechos humanos. Se avanzaría por etapas, que se iniciaban con la convocatoria a las fuerzas políticas y sociales comprometidas en el proyecto de liberación; una vez organizadas, estas elaborarían propuestas que podían llegar a derivar en alianzas electorales como reflejo del trabajo de las estructuras mencionadas. ${ }^{62}$ Solo así el Frente de Liberación Nacional y Social (FLNS) cumpliría su meta al unirse «con la izquierda peronista, el FREPU, los radicales y cristianos consecuentes con la liberación nacional, socialistas y todos los que se comprometieran a luchar». ${ }^{63}$

60 La iniciativa adhesiones del Peronismo de las Bases (sic), Franja Morada Secundarios, Frente Estudiantil para la Participación de la Universidad Nacional de Lomas de Zamora, la Federación Juvenil Comunista, el PC, el Movimiento Defensa del Petróleo Argentino, el Movimiento Peronista 26 de Julio, el MAS, el Po, la Agrupación Peronista 17 de Octubre (de Herminio Iglesias), la Democracia Cristiana de Almirante Brown. Cf. Intransigentes por el Frente, Primer Encuentro Nacional, p. 2. CEDINCI, Col. Volantes. Carpeta 29-PI (1982-2003)

61 Ídem, p. 3.

62 Ídem, p. 8.

63 Ídem, p. 9. 
Como correlato de la asamblea anterior, en marzo de 1987 se llevó a cabo en la provincia de Buenos Aires el I Encuentro Provincial de Intransigentes por el Frente,64 en el cual participaron 85 delegados de 25 distritos. El plenario contó con la participación de un muy amplio arco de partidos de izquierda. Allí se reivindicaron el perfil, los principios y las banderas del PI y se levantó la consigna «Liberación o Dependencia y la socialización de la riqueza, el poder y la cultura». ${ }^{65}$ Decidieron convocar al Peronismo de Base Combativo, que no encontraba su expresión en la Renovación, al Frente del Pueblo, los Radicales por la Liberación, socialistas, cristianos antiimperialistas y a organizaciones intermedias (sindicatos, centros de estudiantes, sociedades de fomento, etcétera).

Pero este sector era uno de al menos tres que por entonces se expresaban dentro del partido y disputaban la identidad intransigente. Junto a él, un sector de la militancia y el VTR proponía aliarse con el cafierismo; estos eran criticados por quienes estaban más a la izquierda como «pseudo dirigentes encaramados en la superestructura del partido», que propiciaban una alianza con el justicialismo al solo fin de conseguir y repartir bancas. ${ }^{66}$ Finalmente, otro grupo proponía mantener el «aislamiento alternativista»; se le atribuía hacerle el juego al bipartidismo en su intento de asegurarse un mínimo espacio. Las divisiones internas impidieron formular un proyecto aliancista claro, de lo que se derivaron distintas interpretaciones: FNLS, «frente con Cafiero», «el PI solo», «frente con Romero en Corrientes», «borrarse en otro frente», etcétera. ${ }^{67}$

No obstante, el PI presentó candidaturas propias a los comicios de 1987 y su performance electoral descendió al 2,84\% en elecciones de gobernador. ${ }^{68}$ El desplazamiento del tercero al cuarto lugar entre las preferencias del electorado a nivel nacional y en la provincia de Buenos Aires fue vivido como una derrota. El partido solo incorporó un nuevo diputado nacional por la provincia de San Juan, que llegó en alianza con el peronismo renovador. La baja performance electoral se debió en buena medida a la volatilidad del voto intransigente, que encontró en un peronismo renovado la opción que satisfaría sus demandas. La lectura de la situación por la dirigencia partidaria fue buscar una alianza con el peronismo. Era un golpe duro para los militantes que se encontraban más a la izquierda, quienes se sumaba al provocado por la sanción de la Ley de Obediencia Debida como resolución de la crisis militar de Semana

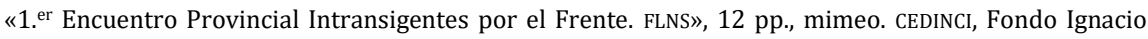
Moiraghi, PI.

Al cerrarse el encuentro había delegaciones oficiales de la UCR Liberación, el PC, MAS, MP 26 de Julio, Corriente Nacional Peronista de las Bases, Corrientes de Base del Frente Popular, PL, PO, ML17 y del Frente Amplio del Uruguay. Ídem, p. 12.

66 Ibídem.

67 Nota de Intransigentes por el Frente, mimeo (c. mediados de 1987). CEDINCI, Fondo Ignacio Moiraghi.

68 http://andytow.com/atlas/totalpais/buenosaires/1987g.html. 
Santa de 1987. En conjunto, provocaron una desbandada de militantes, en especial jóvenes, con lo que el PI perdió gran parte de sus cuadros más activos. ${ }^{69}$

Finalmente en 1989 el PI integró al PJ en el FREJUPO, junto con lo que quedaba de la DC y el Socialismo Auténtico. Las autoridades del partido dispusieron ratificar la fórmula presidencial Menem-Duhalde, facultar a la conducción del comité nacional para confeccionar y aprobar la plataforma frentista, negociar la integración de las listas de candidatos e impulsar la nominación de Alende como candidato a diputado nacional por la provincia de Buenos Aires. ${ }^{70}$ Las gestiones generaron tensiones y conflictos porque algunos dirigentes - como Mariano Lorences y Miguel Monserrat, que habían apoyado integrar un frente con Cafiero pero no con Menem - rechazaban el acuerdo argumentando el abandono de las banderas históricas del partido. ${ }^{71} \mathrm{La}$ conducción explicó que la integración al FREJUPO no se fundamentaba en la búsqueda de cargos «sino en la imperiosa necesidad de unir a los sectores populares para resistir el avance del proyecto neoliberal» que encarnaba el alfonsinismo. ${ }^{72}$

La negociación adoptó distintas modalidades según los distritos; en Catamarca y La Rioja la integración fue resuelta por dirigentes nacionales -Oscar Valdovinos, Marcelo Arabolaza y René Irurzun-; en Buenos Aires y Capital Federal, por las conducciones distritales. Salvo la candidatura de Alende, no se ofrecieron otras diputaciones expectables para el PI bonaerense..$^{73} \mathrm{Se}$ argumentaba que en el frente se habían abandonado los resabios de sectarismo y dogmatismo característicos de la izquierda argentina, ${ }^{74}$ para continuar defendiendo las históricas banderas de unidad nacional, revolución productiva, unidad latinoamericana, moratoria, no a la amnistía.

El ser frentista es una característica esencial de la identidad intransigente. Asumirse como izquierda nacional, popular y revolucionaria significa dejar de lado el dogma vacío y comprender que todo cambio debe impulsarse a partir de la gente. Es la unidad del pueblo real, la de usted y de todos los que padecemos la crisis más grave de nuestra historia, heredada del proceso y profundizada por un

Gabriel Puriccelli recuerda que el partido se desactivó; en los centros de estudiantes de las facultades solo algunos mantuvieron la presencia del PI. En la década siguiente, el partido realizó un fuerte aporte de militantes al Frente Grande. De la entrevista a Gabriel Puricelli, O. cit.

71 Por esa razón, el diputado nacional Miguel Monserrat fue separado de su bloque, integrado por Oscar Alende, José Aramburu, Raúl Rabanaque Caballero y Luis Manrique. Cuestionaba a la dirigencia intransigente haber abandonado las banderas históricas del partido. «Monserrat sin bloque», Clarín, 16.3.1989. Monserrat habría sido marginado por su postura contraria a la alianza con Menem. De la entrevista a Gabriel Puriccelli, o. cit.

72 «Acusaciones en el PI», Clarín, 9.3.1989, p. 15.

73 «Tratan intransigentes la relación con el PJ». Clarín, 17.3.1989. «El PI se pone duro en sus reclamos». Clarín, 18.3.1989.

74 «El PI aprobó el frente», cit. 
gobierno cada vez más alejado de las necesidades populares. El FREJUPO no se reduce a lo electoral, sino que es la herramienta con la que garantizaremos la consolidación y profundización de una democracia social destinada a obtener la independencia económica, asegurar la justicia social y preservar la soberanía política de la nación. ${ }^{75}$

Se reconocía que la coalición arrastraba figuras y concepciones contrarias a los principios intransigentes, pero, se afirmaba, el FREJUPO no era un «modelo terminado» sino el inicio de una posibilidad de construir los objetivos de la liberación nacional. ${ }^{76}$ Había discrepancias con el mismo candidato a presidente, pero se le respetaba que hubiera sido elegido por el voto directo de los peronistas, que se vinculara con los sectores populares y marginados, que no fuera un candidato del poder económicofinanciero nacional e internacional como Eduardo Angeloz o Álvaro Alzogaray, candidatos presidenciales de la UCR y la UCEDÉ respectivamente. ${ }^{77}$ La situación de campaña preelectoral incrementaba las expectativas. En el discurso se sostenía que el FREJUPO permitiría profundizar y consolidar la democracia, rechazar cualquier tipo de amnistía, defender el patrimonio nacional contra la privatización de los sectores estratégicos de nuestra economía, lograr una moratoria de la deuda con tratamiento parlamentario, subordinar las fuerzas armadas al poder civil y rechazar la doctrina de la seguridad nacional, reemplazar la cultura de la especulación por la de la producción, impulsando una auténtica revolución productiva, y promover la unidad nacional y latinoamericana en el camino de la liberación. ${ }^{78}$ Se consideraba que el frente era la expresión de la unidad popular, a la que el PI se integraba con las banderas de la izquierda nacional, popular y revolucionaria, con el fin de impulsar y respaldar las medidas transformadoras y progresistas, apuntando a la consolidación de un gobierno con perfil nacional y popular, la defensa de los derechos humanos y el rechazo a cualquier tipo de amnistía. ${ }^{79}$

Producidas las elecciones, el PI logró renovar la banca de Alende en el Congreso nacional y obtuvo una buena performance en Córdoba y Entre Ríos. No mucho más. El frente no funcionó como una coalición de gobierno. El viraje que imprimió Menem en

75 «El PI en el FREJUPO», volante de campaña. CEDINCI, Col. Volantes. Carpeta 29-PI (1982-2003).

76 «Al FREJUPO con el PI», volante. CEDINCI, Col. Volantes. Carpeta 29-PI (1982-2003).

77 «Menem», volante de campaña. CEDINCI. Col. Volantes. Carpeta 29-PI (1982-2003).

78 «Con la fuerza del pueblo. El PI en el Frente», volante de campaña. CEDINCI. Col. Volantes. Carpeta 29-PI (1982-2003).

79 «El PI y los derechos humanos. Donde hay una necesidad, hay un derecho», volante de campaña (recto). CEDINCI. Col. Volantes. Carpeta 29-PI (1982-2003). En el mismo registro, se solicitaba la restitución de los niños apropiados a sus familias, la libertad a los presos políticos heredados de la dictadura, la investigación de los hechos de La Tablada, el rechazo a la ley antiterrorista, el repudio a los militares golpistas y la plena vigencia de las libertades públicas individuales, a través de una democracia participativa con justicia social. Ídem (verso). 
materia de reforma del Estado y la política de indultos provocó el rechazo de buena parte de los intransigentes. Si bien algunos cuadros se menemizaron -el Chino Navarro y Raúl Rabanaque Caballero, de provincia de Buenos Aires y Capital Federal respectivamente-, pasados los primeros cuatro meses de gobierno un sector intentó romper con el menemismo. Alende apoyó esa postura, lo que explica que dos años más tarde presentara su candidatura a gobernador de la provincia de Buenos Aires contra Duhalde. Pasada esa instancia, la mayoría de los integrantes activos del PI se incorporaron al espacio abierto por el Grupo de los Ocho y la Democracia Popular, el cual en Capital Federal y Buenos Aires pasó a formar el FREDEJUSO, que posteriormente se incorporó al Frente Grande.

\section{Continuidades prácticas y muertes anunciadas. A modo de conclusión}

¿Cuál fue el derrotero de la izquierda democrática y la centroizquierda en relación con el peronismo renovador durante la reconstrucción democrática? El PJ, que en 1985 recuperó la tradición frentista, convocó a otras organizaciones políticas para acompañar y apoyar una propuesta: la propia. Y lo logró cada vez que pudo perfilar un liderazgo dotado de autoridad legítima, capaz de hacer predominar al partido sobre las fuerzas minoritarias de las cuales, entre otras cuestiones, inicialmente necesitó la personería jurídica para emerger como alternativa. Los frentes eran acuerdos entre cúpulas que prometían mantener la identidad de los partidos más pequeños, con ocupación de espacios muy minoritarios en las listas conjuntas. Podían concretarse en distintas arenas — nacional, provincial y aun municipal—, según la elección que estuviera en juego. Suponían coincidencias programáticas, algo distinto de la convergencia de intereses y las alianzas electorales estigmatizadas como partidocráticas, Esto habilita a pensar en un umbral ideológico compartido como expresión política del movimiento nacional, popular y antiimperialista, pero no opaca la instrumentalidad que nutría los cálculos electoralistas.

Los diferentes modos de concebir el frente introdujeron tensiones y conflictos en los partidos minoritarios. Primero porque solo algunos sectores propiciaban el acercamiento con el peronismo y, dentro de ellos, algunos lo hacían con recelos; además, dada la heterogeneidad del abanico peronista, se manifestaban tensiones a la hora de decidir cómo y con quiénes organizar un frente. En el PI, las alternativas de integración con la izquierda o con el peronismo desataron conflictos $y$, en alguna medida, incidieron en la sangría de militantes que abandonaron sus filas. Tanto los representantes de HyL que impulsaron las alianzas de 1985 y 1987 como el sector del PI que respondía a 
Miguel Monserrat buscaron integrar el frente con el sector cafierista de la renovación. En 1988 el triunfo de Menem en la interna del PJ decidió a los primeros a escindirse de su partido y marginalizó a los segundos. Unos y otros confluyeron en distintos armados que derivaron en la formación del Frente Grande.

En suma, el peronismo se constituyó como una versión particular de partido toma todo, entre predominante y hegemónico. Los socios menores no pudieron definir una política de conjunto; su capacidad de agencia los llevó a la fragmentación más que a la unidad y, al no tener el control del gobierno que contribuyeron a elegir, les resultó muy difícil fidelizar adhesiones. Más allá de la voluntad deglutidora del peronismo, sus propias limitaciones también los debilitaron como opción político-partidaria.

\section{Referencias bibliográficas}

Abal Medina, J. M. (2007). «Explicando las causas internas del surgimiento y de la crisis del Frente Grande». En J. M. Abal Medina (comp.). Los senderos de la nueva izquierda partidaria. Buenos Aires: Prometeo.

Aelo, 0. (2012). El peronismo de la provincia de Buenos Aires: 1946-1955. Caseros, Eduntref.

Alonso, P. (2010). Jardines secretos, legitimaciones públicas: El Partido Autonomista Nacional y la política argentina de fines del siglo XIX. Buenos Aires: Edhasa.

Cerro, F. (1983). Qué es el Partido Demócrata Cristiano. Buenos Aires: Sudamericana.

ClÉRICI, P. (2013). «Alianzas cruzadas en Argentina. Una aproximación causal desde la teoría». Ciencia Política, 16, 8-33.

FERRARI, M. (2009). «Entre la reorganización y la derrota: El Partido Justicialista de la provincia de Buenos Aires, 1982-1983». Estudios Sociales, 37, 97-125.

- (2013). «Eduardo Duhalde antes del duhaldismo. Trayectoria individual y transformaciones partidarias (1983-1991)». Nuevo Mundo Mundos Nuevos, (2). doi:10.4000/nuevomundo.65243.

- (2014). «Entre historia y memoria: La política bonaerense desde la reconstrucción democrática, 1983-2001». En O. BARRENECHE (comp.). Historia de la provincia de Buenos Aires, T. 5 (pp. 237-278). La Plata: Unipe.

- (2015). Democracia Cristiana, Partido Justicialista y política de frentes: El Frejudepa en perspectiva histórica. Manuscrito presentado para su publicación.

- (2017). «La Democracia Cristiana argentina durante la dictadura cívico-militar y la transición temprana (1976-1985)». Historia, 50(1).

FERRARI, M., y MELLADO, V. (2016). La renovación peronista: Organización partidaria, liderazgos y dirigentes. 1983-1991. Buenos Aires: Eduntref. 
FERrari, M., y Pozzoni, M. (2014). «Tensiones y conflictos en el peronismo: un análisis a través de la Legislatura bonaerense, 1973-1976». Cahiers des Amériques Latines, 75, 147-176. Recuperado de: http://cal.revues.org/3190.

GHIRARDI, E. (1983). La Democracia Cristiana. Buenos Aires: CEAL.

IVANCICH, N. (2004). «La institucionalización del peronismo antes de Menem». Argentina Reciente: Ideología y Política Contemporáneas, 2, 7-46.

JozAmi, E. (2004). Final sin gloria: Un balance del Frepaso y la Alianza. Buenos Aires: Biblos.

KirchHeImer, O. (1990). «The Catch-all Party». En P. MAIR (comp.). The West european party system. Oxford: Oxford University Press.

LEVITSKY, S. (2005). La transformación del justicialismo: Del partido sindical al partido clientelista, 1983-1999. Buenos Aires: Siglo XXI.

MACOR, D. (2001). «Partidos, coaliciones y sistema de poder». En A. CATTARuzza (dir.). Crisis económica, avance del Estado e incertidumbre política (1930-1943) (pp. 49-96). Buenos Aires: Sudamericana. (Nueva Historia Argentina; 7).

MACOR, D. y TCACH, C. (2003-2013). La invención del peronismo en el interior del país (vols. 1-2). Santa Fe: UNL.

Mainwaring, S. y Scully, T. (eds.) (2010). La Democracia Cristiana en América Latina: Conflictos y competencia electoral. México: Fondo de Cultura Económica.

MALAmUD, A. (2004). «El bipartidismo argentino: evidencias y razones de una persistencia, 1983-2003». Colección, 10(15), 13-43.

Mustapic, A. M. (2002). «Del Partido Peronista al Partido Justicialista: las transformaciones de un partido carismático». En M. CAVAROzZI y J. M. ABAL MEDina (comps.). El asedio a la política: los partidos latinoamericanos en la era neoliberal (pp. 137-161). Rosario: Homo Sapiens.

Nosiglia, J. (1983). El Partido Intransigente. Buenos Aires: CEAL.

Novaro, M. (2002). «La Alianza: de la gloria del llano a la debacle del gobierno».

En M. Novaro (comp.). El derrumbe político en el ocaso de la convertibilidad (pp. 31-105). Buenos Aires: Norma.

Novaro, M., y PALermo, V. (1998). Los caminos de la centroizquierda. Buenos Aires: Losada.

OLlier, M.M. (2001). Las coaliciones políticas en la Argentina. Buenos Aires: FCE.

OstiguY, P. (1997). «Peronismo y antiperonismo: Bases socioculturales de la identidad política en la Argentina». Revista de Ciencias Sociales, 6, 133-215.

PARERA, R. (1986). Los demócrata cristianos argentinos: Testimonios de una experiencia política. T. I. Buenos Aires: Leonardo Buschi.

Persello, A.V. (2004). El partido radical: Gobierno y oposición, 1916-1943. Buenos Aires: Siglo XXI.

SARTORI, G. (1976). Partidos y sistemas de partidos. Madrid: Alianza. 
TCACH, C. (2011). «Pensar las coaliciones en la Argentina contemporánea». Temas y Debates, 15(21), 43-52.

ToRre, J.C. (2002). «Los huérfanos de la política: Sobre los alcances y la naturaleza de la crisis de representación partidaria». Desarrollo Económico, 42(168), 647-665.

Vicente, N. y Conte, A. (2006). Padre de la plaza. Buenos Aires: Galerna.

WyNARCYK, H. (2010). Sal y luz a las naciones: Evangélicos y política en la Argentina (1980-2001). Buenos Aires: Instituto Di Tella, Siglo XXI 